\title{
Erratum to: Gender and Race/Ethnicity Differences in Mental Health Care Use Before and During the Great Recession
}

\author{
Jie Chen, PhD
}

\section{Rada K. Dagher, PhD}

\section{Erratum to: J Behav Health Serv Res DOI 10.1007/s11414-014-9403-1}

Rada K. Dagher's name appeared incorrectly in the original publication of this article. It is correct here.

Address correspondence to Jie Chen, PhD, Department of Health Services Administration, School of Public Health, University of Maryland, 3310A School of Public Health Building, College Park, MD 20742-2611, USA. Phone: +1-3014059053; Email: jichen@umd.edu.

Rada K. Dagher, PhD, Department of Health Services Administration, School of Public Health, University of Maryland, College Park, MD, USA. Phone: +1-301-4051210; Email: rdagher1@umd.edu

The online version of the original article can be found at :http://dx.doi.org/10.1007/s11414-014-9403-1.

Journal of Behavioral Health Services \& Research, 2014. 339. (c) 2014 National Council for Behavioral Health. DOI $10.1007 / \mathrm{s} 11414-014-9413-\mathrm{z}$ 